\title{
In Vitro Evaluation of the Antibiogramic Activities of the Seeds of Myristica fragrans on Food Borne Pathogens
}

\author{
${\text { Iyekhoetin Matthew } \text { Omoruyi }^{1,2 \star} \text { and Oghochukwu Theresa Emefo }}^{3}$ \\ ${ }^{1}$ Department of Microbiology, Faculty of Basic and Applied Sciences, Benson Idahosa University, P.M.B. 1100, Benin \\ City, Edo State, Nigeria. \\ ${ }^{2}$ Department of Food Hygiene and Environmental Health (Toxicology option), Faculty of Veterinary Medicine, P.O.Box \\ 00014, University of Helsinki, Finland \\ ${ }^{3}$ Department of Microbiology, Faculty of Life Sciences, University of Benin, P.M.B. 1154, Benin City, Edo State, Nigeria. \\ E.mail: matthew.omoruyi@helsinki.fi
}

Received $26^{\text {th }}$ March 2012; Received in revised form $25^{\text {th }}$ May 2012; Accepted $30^{\text {th }}$ May 2012

\begin{abstract}
Aim: Foodborne diseases have been shown to have direct impact on the health and welfare of a large number of the world population. The in vitro antibiogramic properties of natural spices (Myristica fragrans) on common food borne pathogen became necessary both in improving food safety and development of new drugs.

Methodology and Results: Test isolates (Staphylococcus aureus, S. epidermidis, Klebsiella pneumoniae, Bacillus cereus, Escherichia coli, Salmonella Typhi and Pseudomonas aeruginosa) were collected from the culture collection unit of the department of Microbiology, Benson Idahosa University, Nigeria. Seeds of Myristica fragrans were extracted by soxhlet extractor using ethanol and water, while the oil was obtained by steam distillation. The extracts and oil were tested against the bacterial isolates using agar well diffusion method at varying concentration $(12.5,25,50$ and 100 $\mathrm{mg} / \mathrm{mL}$ ). The oil of Myristica fragrans was found to have the highest antibiogramic activity on the selected isolates, followed by its ethanolic extract with zones of inhibition ranging from $0-24 \mathrm{~mm}$ and $0-16 \mathrm{~mm}$ respectively. The aqueous extract of Myristica fragrans was found to be effective against $E$. coli, Pseudomonas aeruginosa and Staphylococcus epidermidis only at $100 \mathrm{mg} / \mathrm{mL}$. The MIC was also higher in oil extract of Myristica fragrans compared to its ethanolic and aqueous extracts.

Conclusion, Significance and Impact of study: The oil and aqueous extract of Myristica fragrans showed antibiogramic properties against the bacterial isolates used at different concentrations. Thus, its oil can be used as an alternative to synthetic food preservative found to harbor toxic effects and could also serve as sources for development of new antibiotics.
\end{abstract}

Keywords: Ethanolic extract, Gram positive bacteria, Gram negative bacteria, Minimum Inhibitory Concentration

\section{INTRODUCTION}

The food we eat are rarely if ever sterile. They contain microbial associations whose composition depends upon which organism gain access and how they grow, survive and interact in the food over time. Some microorganisms found in food can be in the dormant or semi dormant form, causing no noticeable metabolic changes while many others present may be of public health significance as they are potential pathogens which produce toxins in food thereby causing illness to its consumers (Uraih, 2004). Because food products are now often sold in areas of the world far distant from their site of production, the need for extended shelf life for these products has also increased. Studies have shown that the outbreaks caused by food borne microorganisms are epidemiologically linked to the consumption of several foods like meat, dairy products, poultry, fruits, chocolate and vegetables (Wallace et al., 2000). Food preservation is the best known approach against preventing such microbial contamination/spoilage in food, and over the years chemical preservatives have been used in for this purpose. Unfortunately, research has found a number of the synthetic chemicals to contain toxic, mutagenic, clastogenic and genotoxic compounds (Farag et al., 1989). This has led to the exploitation of natural agents that can be use in food to mitigate the propagation of food borne pathogens whilst causing no health problems for its consumers. The best choice is to use possible food spices that are commonly used as food additives or flavor enhancer. Myristica fragrans (Nutmeg) a dioecious plant is used locally to add flavor and aroma to food especially during frying and baking. Hence, in this study we aimed at investigating the efficacy of nutmeg oil and its extract on some Gram positive and Gram negative food borne bacteria pathogens, which may also underline its use as an alternative to synthetic food preservative.

\section{MATERIALS AND METHODS}

\section{Collection of sample}

Samples of nutmeg (Myristica fragrans) were bought from 
Oba Market in Benin City, Edo State, Nigeria. The seeds were broken into parts and air dried for six to eight weeks until a constant weight of the samples was obtained. Samples were further grounded using prior sterilized laboratory mortal and pistol prior to extraction.

\section{Test organisms}

The test bacterial isolates used in this study were four Gram negative bacteria (Pseudomonas aeruginosa, Klebsiella pneumoniae, Escherichia coli, and Salmonella Typhi) and three Gram positive bacteria (Staphylococcus aureus, Staphylococcus epidermidis, and Bacillus cereus). These microorganisms were obtained from the culture collection unit of the Department of Microbiology, Benson Idahosa University, GRA, Benin City. The bacterial isolates were maintained and stored in nutrient agar slant at $4^{\circ} \mathrm{C}$ prior to investigation.

\section{Preparation of extract}

The dried seeds of Myristica fragrans were grounded into fine powder and the crude ethanolic extraction was done using $70 \%$ alcohol in a soxhlet extractor. The filtrate was evaporated using soxhlet extractor and was poured into a sample bottle and left opened for 2 days to allow the residual ethanol to escape (Gupta et al., 2008). Ground nutmeg was steam distilled over a 6 hour period by slowly heating the solution to $150{ }^{\circ} \mathrm{C}$ using ethyl ether. The mixture or ethyl ether and Myristica fragrans oil was separated using soxhlet extractor.

\section{Screening for antimicrobial activity}

Samples were screened for their antibiogramic activity using agar well diffusion method (Okeke et al., 2001). Each bacterium was first subcultured in nutrient broth at $37 \stackrel{\circ}{\circ} \mathrm{C}$ for $24 \mathrm{~h}$. One hundred microlitres $(100 \mu \mathrm{L})$ of standardized inoculum (106 CFU/mL; 0.5 MacFarland) of each test bacterium was spread with the help of sterile spreader onto sterile Muller-Hinton Agar (MHA) (Hi-Media) to achieve confluent growth. The plates were allowed to dry and a sterile cork borer (6 $\mathrm{mm}$ diameter) was used to bore wells in the agar. Subsequently, a $50 \mathrm{~mL}$ volume of the oil was introduced in triplicate wells of the agar plates. Sterile DMSO served as negative control. The plates were allowed to stand for at least $1 \mathrm{hr}$ for diffusion to take place and then incubated at $37{ }^{\circ} \mathrm{C}$ for $24 \mathrm{~h}$. The zone of inhibition was recorded to the nearest size in $\mathrm{mm}$ (Norrel and Messely, 1997). The results were expressed in terms of the diameter of the inhibition zone: $<9 \mathrm{~mm}$, inactive; 9 $12 \mathrm{~mm}$, partially active; $13-18 \mathrm{~mm}$, active; >18 mm, very active (Junior and Zanil, 2000).

\section{Determination of minimum inhibitory concentration (MIC)}

The MIC was defined as the lowest concentration that completely inhibited the growth for $24 \mathrm{~h}$ (Thongson et al., 2004). The MIC for the cinnamon, clove, lemon, peppermint and nutmeg oils was determined by the agar well diffusion technique. A two-fold dilution series was prepared to achieve a decreasing concentration range of 10 to $0.625 \%(\mathrm{v} / \mathrm{v})$. A $50 \mathrm{~mL}$ volume of each dilution was added aseptically into the wells of Mueller Hinton agar plates that were already seeded with the standardized inoculums (106 CFU $/ \mathrm{mL}$ ) of the test bacteria. Sterile DMSO, without oil, served as negative control. All experiments were performed in triplicate. The agar plates were incubated at $37{ }^{\circ} \mathrm{C}$ for $24 \mathrm{~h}$. The lowest concentration of oil showing a clear zone of inhibition was considered as the MIC.

\section{Statistical analysis}

The values were recorded as mean \pm standard deviation. The statistical significance of difference in the mean and standard deviation $(P<0.05)$ was analyzed by one-way ANOVA test comparison of each of the test groups and the control using the SPSS 15. Duncan's multiple range was used to compare differences among individual means. Differences were considered significant at $p$ levels $<0.05$.

\section{RESULTS}

The result of the antibiogramic activities of nutmeg extract and oil using agar well diffusion method indicated that the oil, water and ethanolic extract of nutmeg at different concentrations $(100,50,25$ and $12.5 \mathrm{mg} / \mathrm{mL})$ showed varying degree of inhibition on the different test isolates. Figure 1 shows the antimicrobial activity of nutmeg oil on all the test isolates. The zone of inhibition of nutmeg oil ranged from 0-7 mm, $0-15 \mathrm{~mm}, 5-20 \mathrm{~mm}$ and $9-25 \mathrm{~mm}$ at a concentration of $12.5,25,50$ and $100 \mathrm{mg} / \mathrm{mL}$ respectively. Klebsiella pneumoniae exhibited the widest zone of inhibition and susceptibility of $25 \mathrm{~mm}$ at a concentration of $100 \mathrm{mg} / \mathrm{mL}$ for the nutmeg oil (Figure 1) but exhibited a zone of inhibition of $12 \mathrm{~mm}$ for the ethanolic extract of nutmeg (Figure 2) at the same concentration. Nutmeg oil was more potent than all the isolates compared to ethanolic and water extracts of nutmeg, with water extract of nutmeg exhibiting no activity on Klebsiella pneumoniae at all concentrations (Figure 3).

The antimicrobial activity of the oil, ethanolic and water extracts of Myristica fragrans on Pseudomonas aeruginosa is indicated in Figure $\mathbf{1}$ to $\mathbf{3}$. It was observed that nutmeg oil had its activity on the organism in the ranged of $0-11 \mathrm{~mm}$. The $0 \mathrm{~mm}$ was produced at a concentration of $12.5 \mathrm{mg} / \mathrm{mL}$ (Figure 1). The ethanolic extract of nutmeg exhibited its antimicrobial activity at all concentrations. $P$. aeruginosa demonstrated susceptibility to the aqueous extract of nutmeg with a diameter of 13 $\mathrm{mm}$ at a concentration of $100 \mathrm{mg} / \mathrm{mL}$ (Figure 3). Meanwhile on Bacillus cereus, nutmeg oil and ethanolic extract of nutmeg produced zone of inhibition only at a concentration of 50 to $100 \mathrm{mg} / \mathrm{mL}$. The organism was resistant to these extracts at $12.5 \mathrm{mg} / \mathrm{mL}$ and $25 \mathrm{mg} / \mathrm{mL}$. Aqueous extract of nutmeg proved inactive at all 


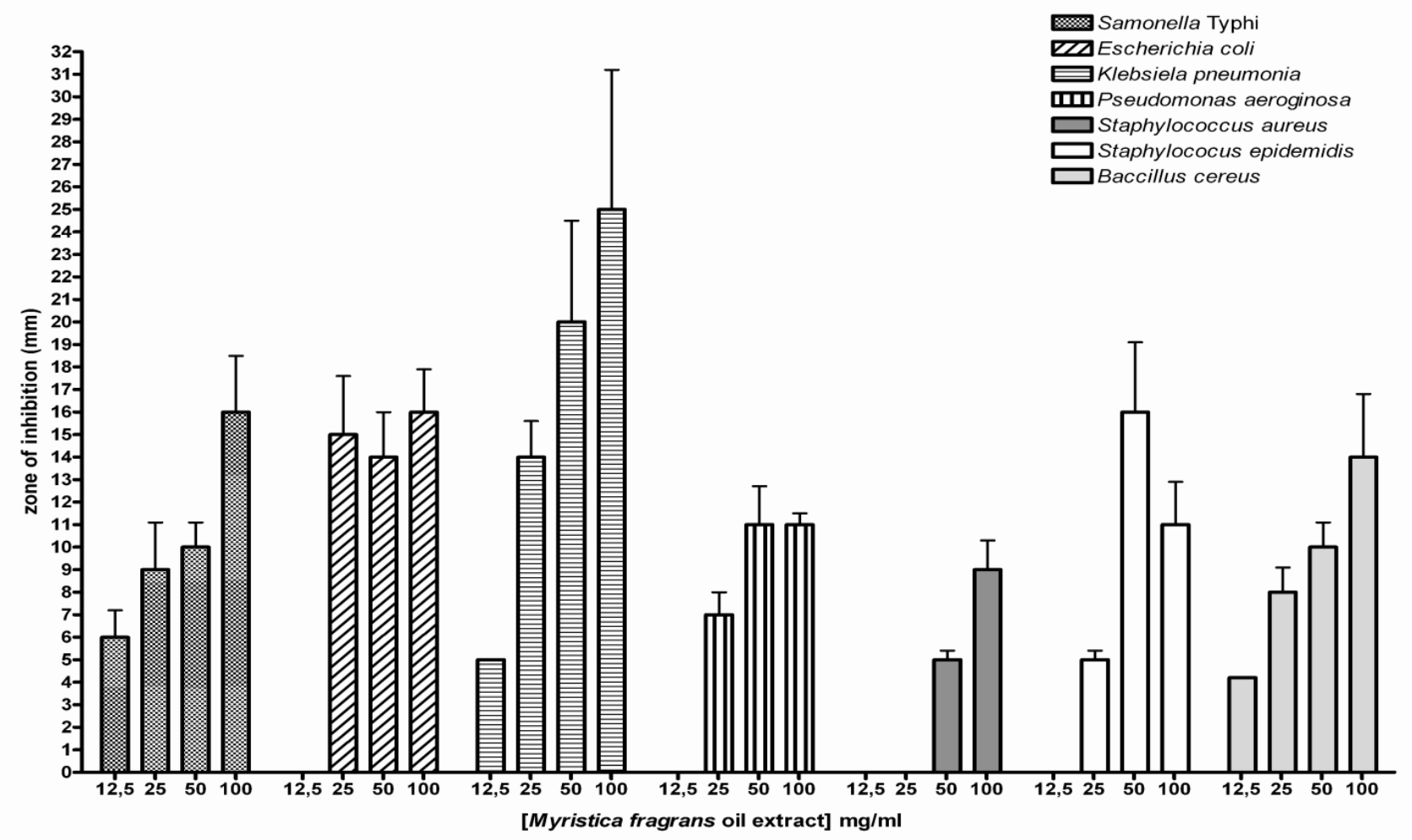

Figure 1: Results of the antibiogramic activity of oil extract of Myristica fragrans on the test isolates

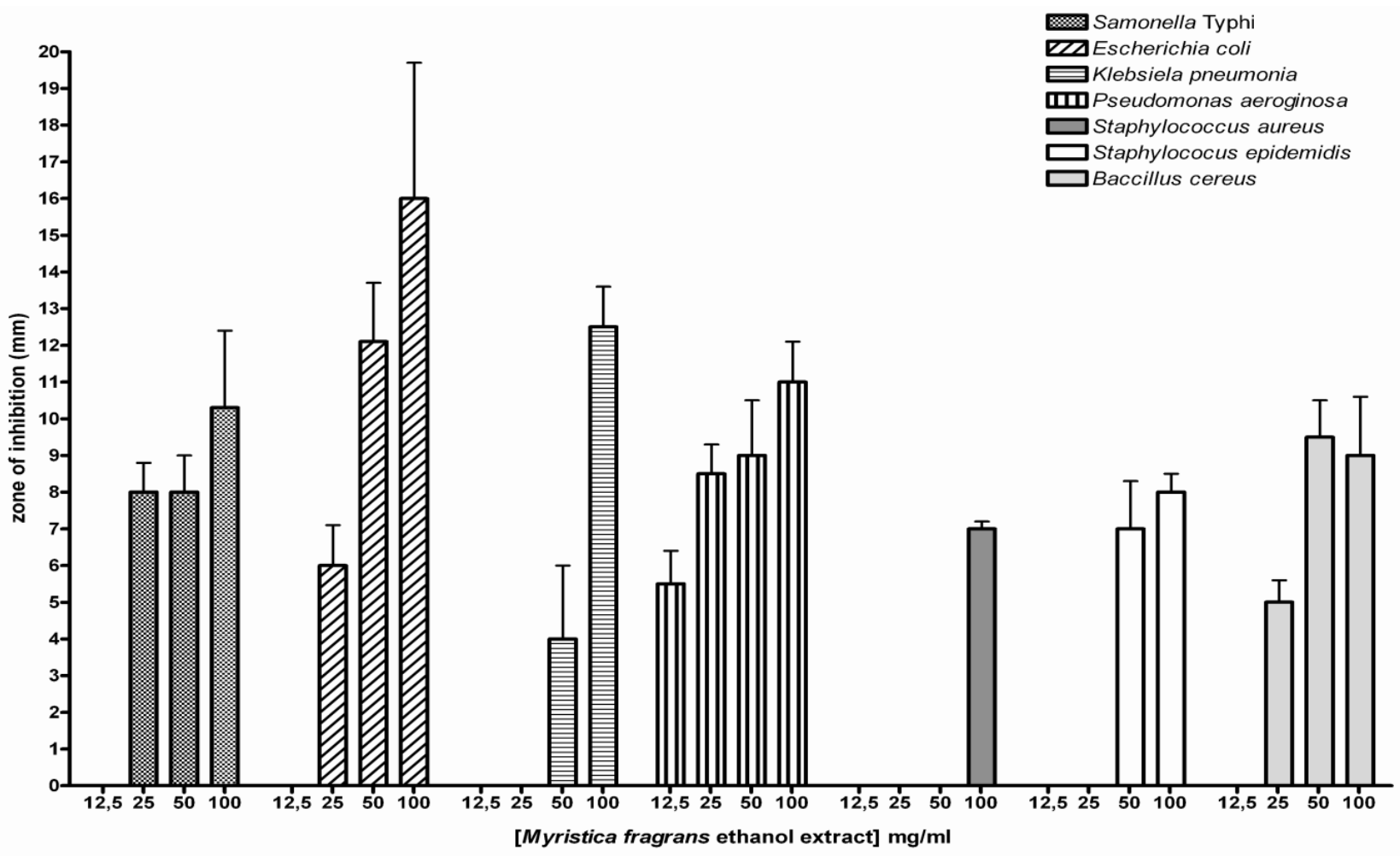

Figure 2: Results of the antibiogramic activity of ethanolic extract of Myristica fragrans on the test isolates 


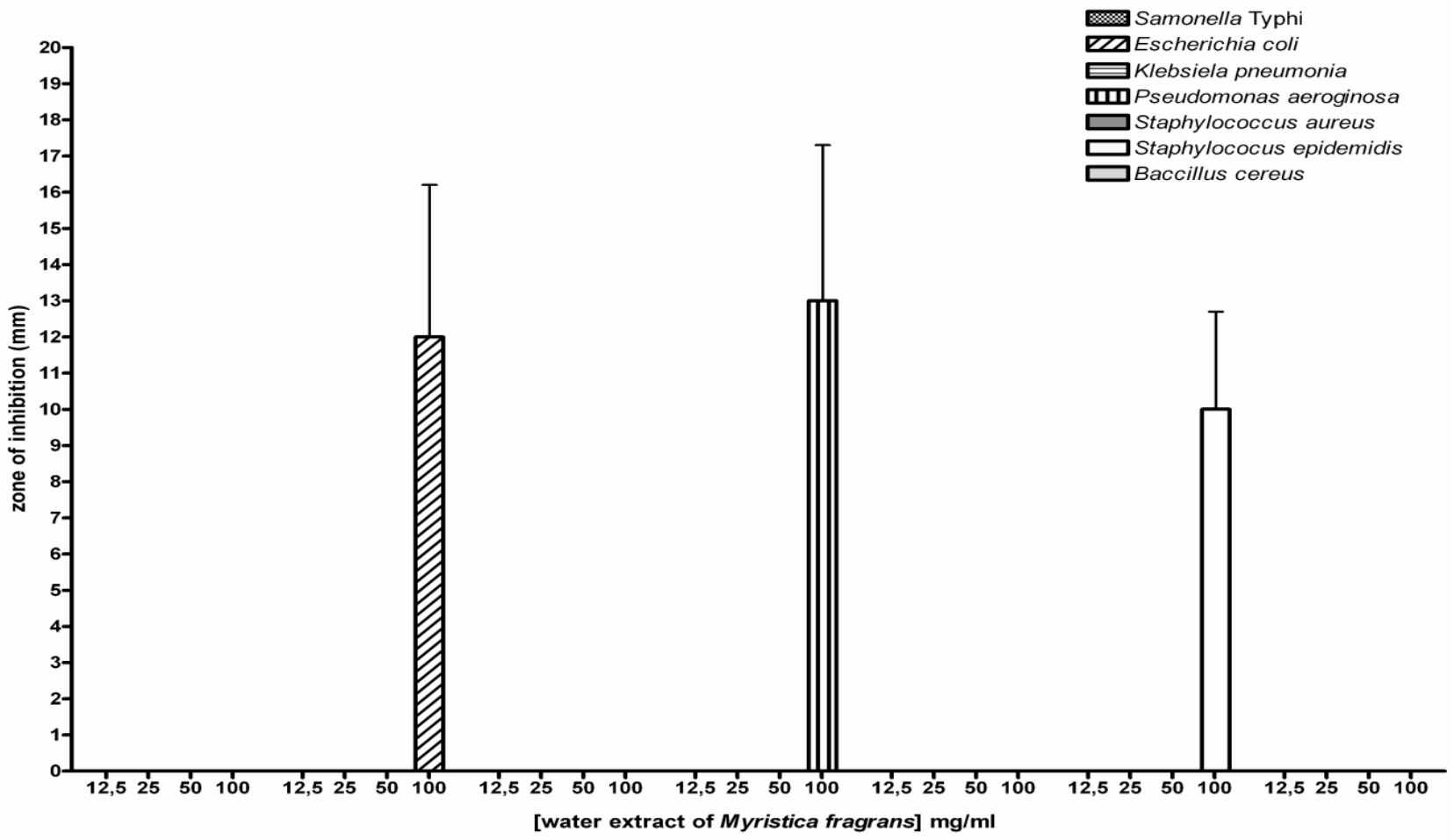

Figure 3: Results of the antibiogramic activity of aqueous extract of Myristica fragrans on the test isolates

Table 1: Results of the minimum inhibitory concentration of the different extracts of Myristica fragrans on the test isolates

\begin{tabular}{|c|c|c|c|}
\hline \multirow[t]{2}{*}{ Bacterial isolates } & \multicolumn{3}{|c|}{$\begin{array}{l}\text { MINIMUM INHIBITORY } \\
\text { CONCENTRATION } \\
\text { (mg/mL) }\end{array}$} \\
\hline & $\begin{array}{l}\text { Nutmeg } \\
\text { Oil }\end{array}$ & $\begin{array}{l}\text { Ethanol } \\
\text { extract }\end{array}$ & $\begin{array}{l}\text { Water } \\
\text { extract }\end{array}$ \\
\hline Salmonella Typhi & $\leq 12.5$ & 25 & $>100$ \\
\hline Klebsiella pneumoniae & $\leq 12.5$ & 25 & $>100$ \\
\hline $\begin{array}{l}\text { Pseudomonas } \\
\text { aeruginosa }\end{array}$ & 25 & $\leq 12.5$ & 100 \\
\hline Bacillus cereus & 50 & 100 & $>100$ \\
\hline Staphylococcus aureus & $\leq 12.5$ & 25 & $>100$ \\
\hline $\begin{array}{l}\text { Staphylococcus } \\
\text { epidermidis }\end{array}$ & 25 & 50 & 100 \\
\hline Escherichia coli & 25 & 25 & 100 \\
\hline
\end{tabular}

concentrations (Figure 3). S. aureus exhibited susceptibility to the nutmeg oil and ethanolic extract of nutmeg to varying degrees with zones of inhibition in the range of $4-14 \mathrm{~mm}$ at concentration range of $12.5 \mathrm{mg} / \mathrm{mL}$ to $100 \mathrm{mg} / \mathrm{mL}$ but was resistant to the aqueous extract of nutmeg at all concentrations. Staphylococcus epidermidis was susceptible to the aqueous extract of nutmeg at a concentration of $100 \mathrm{mg} / \mathrm{mL}$. Nutmeg oil and ethanolic extract of nutmeg exhibited their effectiveness at a concentration range of $25 \mathrm{mg} / \mathrm{mL}$ to $100 \mathrm{mg} / \mathrm{mL}$. The zones of inhibition on Escherichia coli are in the range of 6 - $16 \mathrm{~mm}$ at concentrations of $25 \mathrm{mg} / \mathrm{mL}$ to $100 \mathrm{mg} / \mathrm{mL}$ for both nutmeg oil and ethanolic extract of nutmeg. Aqueous extract of nutmeg exhibits its activity only at a concentration of $100 \mathrm{mg} / \mathrm{mL}$ with zone of inhibition diameter of $12 \mathrm{~mm}$.

\section{DISCUSSION}

The present study reveals the antibiogramic activities of the oil, ethanolic extract, and water extract of nutmeg (Myristica fragrans) against four Gram negative bacteria (Escherichia coli, Salmonella typhi, Klebsiella pneumoniae and Pseudomonas aeruginosa) and three Gram positive bacteria (Staphylococcus aureus, Staphylococcus epidermidis and Bacillus cereus). Sensitivity and MIC testing indicated that the nutmeg oil and ethanolic extract of nutmeg (Myristica fragrans) possess significant amount of antimicrobial activity on all the tested bacterial isolates compared to the water extract. The degree of antimicrobial activity was considered from the MIC values against the bacteria tested. The MIC of the nutmeg oil was in the range of $<12.5$ to $50 \mathrm{mg} / \mathrm{mL}$, ethanolic extract, $<12.5$ to $100 \mathrm{mg} / \mathrm{mL}$, and water extract in the range of 100 to $>100 \mathrm{mg} / \mathrm{mL}$.

Some bacterial isolates showed some resistance when tested against nutmeg oil, and the ethanolic extract of nutmeg at low concentrations. The resistance of these isolates may be attributed to the complex nature of the cell wall, which makes it difficult for the active components of 
the extract to enter into the organism at such concentration Souza et al., (2005). The cell wall serves to protect the intracellular functional components of the cells thereby exhibiting cellular resistance that was observed (Seepersad, 2008). A possible future investigation may reveal that if the concentrations of the extracts used are increased, the structural components of this microbe may be weakened including cellular malfunctioning, inhibition and possible cell death, thereby increasing the rate of susceptibility. Weaker cells allow easy access of antimicrobial agent into the intracellular components of the bacterial cell and this induces the inhibitory activity on the microorganisms, thereby leading to cellular inhibition and death (Chan et al., 1993).

In the present study, the essential oil of nutmeg has proved to be the most effective on all the test organisms as reported in similar studies on the oil extract of other spices (Souza et al., 2005), followed by the ethanolic extract then the water extract of nutmeg. This result is in agreement with that of Nanasombat and Lohasupthawee (2005) who reported that the antimicrobial property of spices is attributed to the essential oil fraction. This is because of the fact that some essential oils contain active components which influence certain metabolic functions of microbial cells.

The results of this study can be related to previous research conducted on the volatile oil of the spice. Previous studies on the phytochemical properties of nutmeg (Myristica fragrans) showed that the antimicrobial activity of nutmeg originated from the volatile essential oil which contains the active components; monoterpene hydrocarbon (61-88 \% e.g $\alpha$-pinene, $\beta$-pinene, and sabinene); oxygenated monoterpenes (5-15\%) and aromatic ethers (2-18 \%) which include myristicin, elemicin and safrole (De Guzman and Siemonsma, 1999; Ahmad et al., 2005). Nakatani (2003) had earlier proposed that the monoterpenes present in nutmeg shows promising antimicrobial activity. This claim however, was to a great extent validated by the antimicrobial activity observed during this investigation on nutmeg (Myristica fragrans). The inhibitory action of the essential oils in nutmeg and their chemical constituents has been hypothesized to sensitize the phospholipid bi layer of the microbial cytoplasmic membrane causing increased permeability, reducing the availability of vital intercellular substance thereby depriving the cell of nutrients which led to impaired bacterial enzymes function and eventual overall cellular collapse and death (Juven et al., 1994; Kim et al., 1995).

Reports by Lattaouri and Tantaoui (1994) stated that essential oils containing eugenol (as in the case of nutmeg) possess significant antimicrobial activity due to hydrophobicity and partitioning in the microbial plasma membrane. The penetration of the essential oil molecules into the plasma membrane affects the proton motive force, intracellular adenosine-triphosphate (ATP) content and the overall functioning of cellular activity including turgor pressure control, solute transport and metabolic regulation (Lanciotti et al., 2004). Prolonged or irreversible failure in one or more of these systems was detrimental to living cells. It was thereby concluded that the weak cellular stability of Gram negative microorganism resulted in an increased amount of eugenol molecules penetrating the cell leading to cellular malfunctioning and eventual death.

Microbial resistance was observed most frequently among the water extract. This may be because this medium is not effective enough to allow the release and activation of the active compounds in nutmeg or may be an insufficient concentration of the extract was used to induce inhibitory effects. Subsequently, a higher concentration of the water extract is recommended. The result obtained from the statistical analysis using Duncan's and least significant difference test indicated that there is a significant difference between the nutmeg oil, ethanol and water extracts on all the test isolates

The overall effectiveness of the ethanolic extract of nutmeg and nutmeg oil against the different food borne pathogens indicates the potential of nutmeg to be use in food industry as a better alternative to synthetic food preservatives, which are known to have side effects. Hence, it can be use to increase the shelf- life of food products and also reduce the rate and incidence of food borne illnesses.

\section{CONCLUSION}

The results from this study showed that nutmeg oil and the ethanolic extract of nutmeg can inhibit the growth of both Gram positive and Gram negative bacteria. The inhibitory effect of this oil is an indication that it can be considered for use as alternative food preservative and as sources for the development of new antibiotics.

\section{REFERENCES}

Ahmad, T.S., Latif, A., Quasmi, I.A. and Amin, K.M.Y. (2005). Complementary and Alternative Medicine. Aligarh Muslim University, Aligarh, India. pp 109.

Chan, E.C.S., Pelzar, J.M.I and Krieg, R.N. (1993). Laboratory Exercises in Microbiology. $6^{\text {th }}$ edition. McGraw-Hill Incorporation, New York. pp 630.

De Guzman, C.C. and Siemonsma, J.S. (1999). Plant resources of South-east Asia spices 13: 67 - 69.

Farag, R.S., Daw, Z.Y., Hewedi, F.M. and EI-Baroty, G.S.A. (1989). Antimicrobial activity of some Egyptian spices essential oils. Journal of Food Protection 52: 665 - 667.

Gupta, C., Garg, P.A., Uniyal, C.R. and Kumari, A. (2008). Antimicrobial activity of some herbal oils against common food-borne pathogens. African Journal of Microbiology 2: 258 - 261.

Juven, B.J., Kanner, J., Schved, F. and Weisslowiez, H. (1994). Factors that interact with the antibacterial action of thyme essential oil and its 
active constituents. Journal of Applied Bacteriology 76: 626 - 631.

Kim, J., Marshall, M.R. and Wei, C. (1995). Antibacterial activity of some essential oil components against five food-borne pathogens. Journal of Agricultural and Food Chemistry 43(11): 2839 - 2845.

Lanciotti, R., Gianotti, A., Patrignani, N., Belleti, N., Guerzoni, M.E. and Gardini, F. (2004). Use of natural aroma compounds to improve the shelf-life of minimally processed fruits. Trends in Food Science and Technology 15: 201 - 208.

Lattaouri, $\mathbf{N}$ and Tantaoui-Elaraki, F. (1994). Individual and combined antibacterial activity of the main components of three thyme essential oils. Rivista Italiana Epposs 8: 13 - 19.

Nakatani, N. (2003). Biologically malfunctioning constituents of spices and herbs. Japanese Journal of Nutrition and Food Science 56: 389 395.

Nanasombat, S. and Lohasupthawee, P. (2005). Antimicrobial activity of crude ethanolic extracts and essential oils of spices against Salmonella and other Enterobacteria. Journal of Science and Technology 5(3): 527 - 538.

Seepersad, K. (2008). The Antimicrobial activity of five food spices when tested against various Gram positive and Gram negative microorganisms. Journal of Agricultural Food Chemistry 52: 539 544.

Souza, E.L., Stanford, Y.L.M., Lima, O.E., Trajano, V.N. and Filho, B.J. (2005). Antimicrobial effectiveness of spices: an approach for use of food conservation systems. Brazilian Archives of Biology and Technology 48(4): 549 - 558.

Uraih, N. (2004). Food Microbiology. Bobpeco Publishers, Benin City, Edo State, Nigeria. pp 120 - 125.

Wallace, D.J., van Gilder, T., Shallow, S., Florentino, T., Selger, S.D., Smith, K.E., Shiferaw, B., Etzel, R., Garthright, W.E., Angulo, F.J. and Group. F.W. (2000). Incidence of food-borne illness reported by the food-borne diseases active surveillance network. Journal of Food Protection 63: 807 - 809. 